\title{
Activity Based Costing (ABC): Is It a Tool for Company to Achieve Competitive Advantage?
}

\author{
Desti Kannaiah $^{1}$ \\ ${ }^{1}$ School of Business, James Cook University, Singapore Campus, Singapore \\ Correspondence: Desti Kannaiah, Senior Lecturer, School of Business, James Cook University, Singapore \\ Campus, Singapore. E-mail: kannaiah.desti@jcu.edu.au
}

Received: October 2, 2015

Accepted: October 26, 2015

Online Published: November 25, 2015

doi:10.5539/ijef.v7n12p275

URL: http://dx.doi.org/10.5539/ijef.v7n12p275

\begin{abstract}
Most of the companies today have no idea what their products cost them to make. Usually companies think they do know but unfortunately they are not correct. This misunderstanding has led many business organizations to make decisions that are bad to the business. They might abandon profitable products in favor of products that are losing money. However, the companies' cost information just does not help! Generally managers receive cost information that is misleading and harmful, and make them do the wrong things in their work place.

This damaging information comes from full absorption costing (both fixed and variable costs) of calculating total product costs. The costing system calculates product costs by allocating a portion of the overhead or indirect costs to each products being manufactured. The amount of the overhead cost allocated is based on the amount of direct hours or direct labor costs required to make the product. This method of allocating is a good approach of allocating overheads many years ago when direct labor was the largest portion of cost required to make a product and when overheads were small.

The problems associated with this allocation methods were highlighted in the late 1980s with the publication of the influential book "Relevance Lost; the Rise and Fall of Management Accounting" by Tom Johnson and Bob Kaplan. Johnson and Kaplan showed that the historical development of cost and management accounting has given rise to inappropriate methods of allocating overhead costs. These methods of allocation lead to cost distortion. This resulted in managers making the wrong strategic decision. The overall objective of this study is to investigate and assess how $\mathrm{ABC}$ provides the company with additional competitive edge to compete in the globalization environment.

The principle of activity-based costing has been a much talked about tools in the 1980s and 1990s. But is ABC really the strategic tool to achieve competitive advantage as expected? How the companies should approach the implementation of $\mathrm{ABC}$ in order to achieve the required results. What the companies should expect from the $\mathrm{ABC}$ ? What is the future of $\mathrm{ABC}$ ?
\end{abstract}

Keywords: absorption costing, marginal costing, full cost, competitive advantage, cost drivers, cost allocation

\section{Introduction}

Activity-based costing $(\mathrm{ABC})$ is a costing methodology that identifies activities in an organization and assigns the cost of each activity with resources to all products and services according to the actual consumption by each.

$\mathrm{ABC}$ is the process of identifying and assigning costs to specific activities within functions and work processes. The approach allows the costs to be differentiated by individual products or customers based on the effort and resources required by each.

The basic principles of $\mathrm{ABC}$ are:

Principle 1: Activities consume resources.

The more an activity is performed, the more resources will be consumed by it.

Principle 2: Activities have a cause.

Principle 3: Customer, products, or channels cause different levels of activity.

Traditional costing methods, such as absorption costing, allocate base cost directly to products, customers or 
distribution channels. It ignores the principle that resources are actually consumed by activities and not by the products, customers and channels. $\mathrm{ABC}$ allocates costs to customers' products and channels base on the proportion of activity they actually consume.

Figure 1 showed how the three principle works.

Activities Tracing resource cost to activities

Tracing activity cost to cost objects

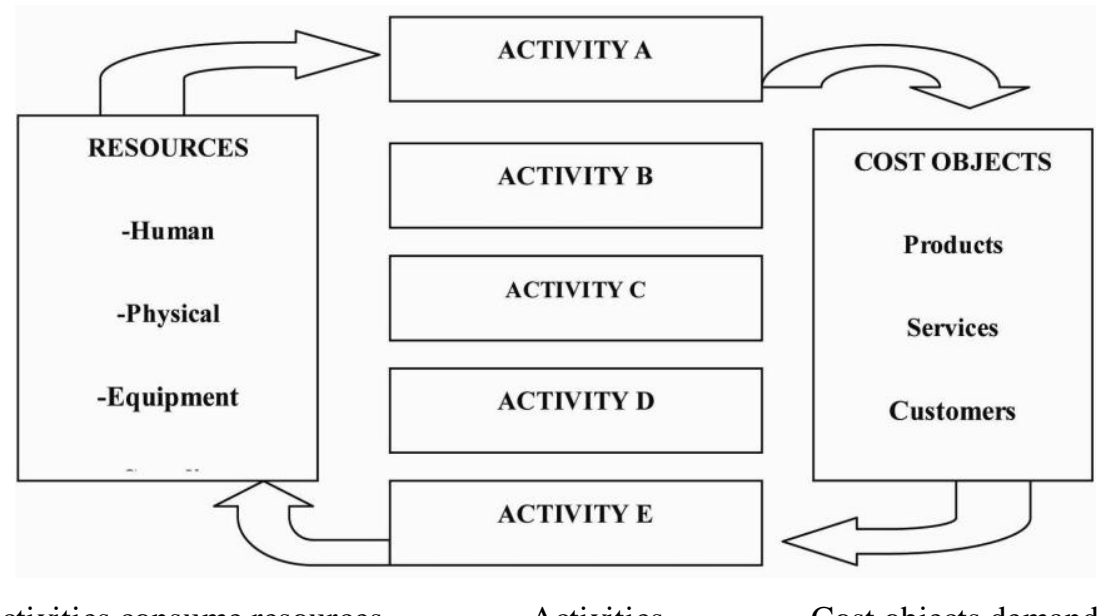

Activities consume resources

Activities

Cost objects demand

Figure 1.

The overall objective of this study was to investigate and assess how ABC provides the company with additional competitive edge to compete in the globalization environment. It also aim to identify the reasons on why despite the many advantages of $\mathrm{ABC}$, it adoption rate had been declining ever since it inception by its founding father of $\mathrm{ABC}$, Robert S. Kaplan.

Within this overall objective a number of specific issues were highlighted, including:

- Who initiated and championed the introduction of activity-based techniques;

- The uses to which activity-based techniques were put and the development which took place within each company;

- Changes in attitudes towards activity-based techniques which occurred after implementation;

\section{Literature Review}

Companies can reap enormous advantages from doing this, as Japanese firms demonstrated in the 1970s and 1980s with such practices as total quality management and continuous improvement. But from a competitive standpoint, best practices are easily emulated. As all competitors in an industry adopt them, there is no relative advantage which make you the leader in the marketplace. In order to achieve true and sustainable competitive advantage over its rivals, a company strategic positioning must be to preserve what is distinctive about a company. It means performing different activities from rivals, or performing similar activities in different ways. Sun Tzu says that "unexpected or innovative tactics cannot be defended in advance. Innovation is one weapon that makes you invincible. The power of innovation makes victory certain." Effective innovation is not necessarily complicated or difficult. The advantages of $\mathrm{ABC}$ and other management tool such as Total Quality Management and Process Re-engineering have shown the value of improving the company performance. (Donald G. Krause, 1996, p. 114; Shaman, 2002).

Today, there is an increasing understanding that rising revenue does not necessarily drive profitability. The extended economic boom has attracted new competitors into the markets. With a weaker economy, both established and new companies are locked in competition and margins are under pressure as they fight to command this reduced demand. The pressure on companies to understand how they operate and where they generate their profits from has become greater as the competitive environment has become harsher.

Success-let alone survival - in this new competitive environment are no longer assured. Successful companies need to develop a new way of doing business. To achieve this company has to undergone fundamental changes in 
managing their business. Company need not only to satisfy the needs of the customers but they need to achieve this profitably. Everyone needs to commit to improving continuously in the company.

With today's global business environment, competition is without boundaries. To be able to survive in this fierce competitive arena, company needs not only to understand external situation but it also need to understand and re-look at its sources of information, especially the cost information. "To achieve success, you must manage information. Information is the lifeblood of business". Sun Tzu says that information, or lack of it, determines the probability of success. (Donald G. Krause, 1996, p.111) Company which does not have timely, accurate information could well be in the losing battle. "That's no small matter in today's competitive environment. What's at stake is nothing less than your survival", says Ron Dye, the Leonard Spacek Professor of Accounting and Information Systems at Northwestern University's Kellogg Graduate School of Management. (Karen Titus, 2002).

Deinzer, president and chief executive officer of the Clifton, New Jersey-based steel firm, has been asking his colleagues whether they are making money out of their customers. He has a feeling that, "We are shipping steel out the door with dollars bills wrapped around it". (Karen Titus, 2002).

It is clear that yesterday's cost systems do not work in today's competitive environment. How the companies are coping with the competitive challenge depend very much on the strategy in doing business. It is to ensure continuous improvement in all aspects of a company's business. And the goal of the company is to profitably meet the needs of its customers.

But, new ways of conducting business demand new ways of measuring performance. The company needs information that:

Shows what matters to its customers (such as quality and service),

Reveals how profitable its customers and products are,

Costs a reasonable amount to report,

Identifies opportunities for improvement, and

Michael Porter stated in his book Competitive Advantage, "While accounting system do contain useful data for cost analysis, they often get in the way of strategic cost analysis" (Michael Porter, 1998).

\section{Why Do Companies and Organizations Use Activity Based Costing?}

Management is moved to adopt $\mathrm{ABC}$ by the desire to improve costing accuracy—get closer to the true cost and true profitability - of individual products and services, or to understand better the true costs and return on investment from projects or other initiatives. $\mathrm{ABC}$ gets closer to true costs in these areas by turning many costs that traditional cost accounting treats as indirect costs essentially into direct costs. Examples below show how this is done.

In organizations where $\mathrm{ABC}$ has been implemented successfully, activity based management uses the approach to support decisions about pricing, adding or deleting items from the product portfolio, choosing between outsourcing and in-house production, and evaluating process improvement initiatives.

The percentage of organizations currently using activity based costing varies greatly from industry to industry. Various surveys in the period 2010-2014 report the highest percentage of organizations using ABC in manufacturing (20\%-50\%), followed by financial services (15-25\%), public sector (12-18\%), and communications $(6-12 \%)$.

Is $\mathrm{ABC}$ the solution? As mentioned above to be competitive, a company must know its sources of profit and its cost structures.

The primary use of $\mathrm{ABC}$ shifts from that of an accounting tool to that of a management decision support system. This provides valuable business intelligence. The information produced by ABC improves operational, tactical and strategic decisions and enhancing companies cost control. It is a strategic tool which allows company to achieve competitive advantage. It enables the companies to recognize the factors that influence cost dynamics in both the short and long term. The need for $\mathrm{ABC}$ in strategic cost management in this competitive environment has never been greater.

What is the strategic value of $\mathrm{ABC}$ ? What is the ways in which $\mathrm{ABC}$ provides companies with the added competitive advantage?

$\mathrm{ABC}$ is a valuable tool for enhancing the top line and bottom line the same time. It allows the companies to set competitive pricing. $\mathrm{ABC}$ provides data on what constitutes the minimum cost for a particular job. Therefore it 
allows companies to provide the baseline setting for the price. Companies can go into a bid with a price that is low enough to win the contract, and yet exceeded the contract's $\mathrm{ABC}$ cost.

$\mathrm{ABC}$ allows companies to review its products for price adjustment. In some cases, $\mathrm{ABC}$ may reveal the opportunities to reduce cost via better product design and continuous process improvement. The customers will be benefited from it. The rate of customer retention will increase and company will improve its competitive position.

During the early 2000s, Blue Cross and Blue Shield of Florida, Inc. faced an increasingly competitive and complex marketplace for healthcare products and services. Its management initialed "The cost for pricing" project in response to the competition. The aim of project is to employ $\mathrm{ABC}$ to radically look at its cost structure so that a competitive pricing would be set. The benefit of cost for pricing is to provide the strategic activity cost information for the company's management the needs to manage the business. The goal is to provide the right information at the right time to the right people in a cost-efficient way. The cost for pricing is designed to be flexible and adapt to changes in strategies and cost information needs for the managers who use the information to help identify market opportunities and to operating issues. With the information generated from the $\mathrm{ABC}$ system, the price was more competitive than before. The managers were more confident now when pricing its product. (Kenneth L. Thurston et al., 2000).

In Peter Francese's book, Marketing Know-How, he posed key questions around a customer/marketing model which basically instructs marketers to "follow the money". Francese starts by asking what kinds of customers are loyal and profitable.... And what kinds are only marginally profitable, or worst yet, losing you money. (Peter Francese, 2002).

According to Martin Lynch of AXA PPP Healthcare: "How can customer relationship management (CRM) exist without ABC being in place first?". Some analyst estimate that 65-80 percent of CRM projects fail. Gartner estimates that this figure will grow to 80 percent by 2003 . There are many potential reasons, but they boil down to the fact that knowing more about a customer is not an automatic route to profit. CRM may give more information on customer behaviour and identifies opportunities to sell, but without an understanding of the costs of the companies there is no guarantee that selling an extra product will be profitable or it may reveal which product will be the "next most likely to buy", but it will not reveal whether selling it to that customer will be a profitable exercise.

A report from Ernst and Young, showed that only 20 percent of the companies could say that their investment in CRM has led to a profitable outcome; 63 percent have no idea whether it has in fact led to a profitable outcome or not. (Financial World, 2002).

\section{Competitive Analysis}

$A B C$ can be used to understand competitor profitability as well as your own. The knowledge gained can be used to make selective price changes, change marketing emphasis, enter new markets, or counter unfair competitive actions.

For example, Parts Maker, Inc which was a \$24 million manufacturer of parts and assemblies for automobile used $\mathrm{ABC}$ to study the manufacturing and distribution costs of products sold by competitors. $\mathrm{ABC}$ can provide insights for determining the likely activities to build and distribute these competing products. Cost will then built from the activity information, and cost data from annual reports. The analysis will assist company to understand their position when compare to their competitors. Whether the company should assess its price relative to its competitor's, the potential for market-share gains, and the need for reductions in the cost of distribution activities. (Institute of Management Accountants, 2002).

\section{Research Methodology}

The main objective of the research is as follows:

- To identify and determine the reasons company implement $\mathrm{ABC}$

- To identify the key differences between companies which are successful in implementing $A B C$ and those which fail.

- $\quad$ Attempt to demonstrate how ABC improve company's competitive advantage.

A total of 105 surveys were conducted by various methods in order to ensure that responses are gathered from diversified sources. Questionnaires are sent to targeted respondents from various industries who are accounting professional and managerial staff who are involved in decision making. These industries include information technology, services, and manufacturing. Interviews were also conducted at the research site to gather valuable 
opinions from people who are personally involved in the implementation. They are either from the management, operational, administrative or accounting department.

\subsection{Research Methods}

The research methods are as follows:

- Questionnaire;

- Interview.

\subsection{Questionnaire}

The questionnaire survey consists of wide range of questions but is concise and relevant. It contains 14 questions focusing on the following areas:

- The existing conventional costing system.

- $\mathrm{ABC}$, the tool to achieve competitive advantage.

- Applicability of $\mathrm{ABC}$.

- Implementation of $\mathrm{ABC}$

The survey avoided questions regarding proprietary cost information or topics which could potentially be considered sensitive by the respondents.

Respondents are given more than 4 selections to choose from so that it would sufficiently answer to the question asked. It is also appropriately structured to allow respondents of different experience and level in the decision making hierarchy to understand without any difficulty.

The questionnaire was sent to the participants via electronic mail, by post or by hand. Completed questionnaire were returned directly via electronic mail, by post or by hand.

\subsection{Interview}

This is done by calling companies or persons targeted or recommended by people who are aware of companies either planning to implement or had implemented ABC. This also includes interview conducted in the course of the case study.

\subsection{Response Rate}

Of the 80 questionnaire sent out, 46 or $58 \%$ responded. Of the 15 interviews conducted through telephone, 6 companies or $46 \%$ were willing to accept the interview whereas others rejected either because they had no comment or stated confidentiality as a reason. Interview conducted during the case study was much successful with $100 \%$ (10 out of 10) agreed to be interviewed. The total response rate from the three type of survey yielded $59 \%$ or 62 out of 105 responded.

\subsection{Limitation of Research}

Results from the survey may not be representative of the population because of several limitations.

Firstly, some respondents might not have taken the questionnaires seriously as some were done by students. Also, this is for academic purpose and there is no personal incentive for the respondents to cooperate.

Secondly, though the author has taken steps to minimize ambiguity in the questionnaire, there might still have been some differences in the interviews' and the respondents' perception and interpretation of the questions.

The survey results shows that there is an concurrence that a good costing system such as ABC will definitely armed the company with sufficient bullets to compete in a competitive arena. However, companies also acknowledge that to implement $\mathrm{ABC}$ is a daunting task. The process can place a significant burden on a company. They were rather weigh the benefit and cost instead of blindly following the trend of the "latest management tool".

However, if such implementation is carried out progressively or for a section of the company operation, the success rate will be enhanced. $\mathrm{ABC}$ is used only to price its services to the customers with the intention to extend the implementation to other area in the business.

The questionnaire and telephone survey suggested that the key to the success of implementing $\mathrm{ABC}$ is to obtain the support of all level of employees. Research demonstrated that without this support there is no way that it will be accepted and implemented successfully.

$\mathrm{ABC}$ implementation entails a long process any attempt to accelerate the acquisition of expertise by relying on 
outside consultants will most likely faced with difficulties. Generally consultants provide canned solutions. Further-more, anyone who plans and designs an $\mathrm{ABC}$ model gains an enormous amount of knowledge about their company's products and activities. If a consultant does the bulk of the planning, that knowledge leaves with the consultant when the job is done.

But if you are the primary planner, even under the guidance of a consultant, the knowledge stays with you, in your organization. It then becomes an information base for strategic and cost-reduction decisions.

\section{Conclusion and Recommendation}

$\mathrm{ABC}$ should not be the only tool that provides companies with the competitive edge. $\mathrm{ABC}$ cannot solve all the problems in your company. $\mathrm{ABC}$ is just one of the tools which complement and enhance other management tool such as Six Sigma, Business Process Re-engineering, and Total Quality Management. It is one of the tools which help managers to formulate and make strategic decision. Companies need to ensure that whichever management tools it uses; it must complement and supplement each other so that it can reap maximum benefit.

In implementing $\mathrm{ABC}$ to achieve the company's goal, it must have a practical mindset. $\mathrm{ABC}$ system is just "a machine" it does not think for you, perform work for you or resolve problems by itself. $\mathrm{ABC}$ requires knowledgeable, talented people to interpret and use the information from the $\mathrm{ABC}$ system to make strategic decision. Therefore if the companies can apply right tool in the right way to the right problem and with the right mindset it will consistently produce the right results.

$\mathrm{ABC}$ is used in a number of ways to support manufacturing excellence. $\mathrm{ABC}$ provides information for strategic decisions, such as product mix and sourcing decisions, that is consistent with the long-run nature of these decisions. $\mathrm{ABC}$ allows product designers to understand the impact of different designs on cost and flexibility and modify their designs accordingly. ABC supports the continuous improvement process by allowing management to gain new insights into activity performance, by focusing attention on the sources of demand for activities and by permitting management to create a behavioral incentive to improve one or more aspects of manufacturing. $\mathrm{ABC}$ is a tool for managing complexity in manufacturing. $\mathrm{ABC}$ provides activity-based information to help managers understand and eliminate complexity. The benefits of $\mathrm{ABC}$ can be achieved without designing a system that is more complex than necessary. The $\mathrm{ABC}$ designer can use the rules of $\mathrm{ABC}$ design to simplify the system without sacrificing the accuracy of product cost.

Good people can only be good if they are properly train with the positive mindset and belief. As companies become more globalize, they will face with stern competition from around the world. The way of doing business vary depending on the intensity of competition, the type of industry the company is in. With the technology advances, the demand for relevant strategic information will increase. Companies will increasingly look to information and information technology for competitive advantage. To survive in this competitive arena, the company needs to analyze how they can access strategic information? How to put this information into strategic use?

$\mathrm{ABC}$ should not be the only strategic tool for company to achieve competitive advantage. The use $\mathrm{ABC}$ should complement other management tools so that overall competitive advantage can be achieve. The information from the $\mathrm{ABC}$ should serve as a basis or platform and may be combined with other strategic tool for the companies to devise a strategy plan to compete effectively and efficiently.

\section{References}

ABC Technologies. (2002). ABC Gathers Speed At Mobil. Retrieved from https:// www.iepg.unifei.edu.br

Adams, M. (1996). Activity-based costing (ABC) and the Life Insurance Industry. The Service Industries Journal, 16(4), 511-526. http://dx.doi.org/10.1080/02642069600000044

Anderson, S. R., \& Kaplan, R. S. (2004). Time-driven activity-based costing. Harvard Bus. Rev., 82, 131-138.

Baird, K. M., Harrison, G. L., \& Reeve, R. C. (2004). Adoption of activity management practices: A note on the extent of adoption and the influence on organizational and cultural factors. Management Accounting Research, 15, 323-399. http://dx.doi.org/10.1016/j.mar.2004.07.002

Cooper, R., \& Kaplan, R. S. (1988). How cost accounting distorts product costs. Retrieved from http://www.http://coin.wne.uw.edu.pl/

Horgren, C. T. (1995). Management accounting: this century and beyond. ManagementAccounting Research, 6, 281-286. http://dx.doi.org/10.1006/mare.1995.1019

Institute of Management Accountants. (2002). Implementing Activity-Based Costing. Retrieved from 
http://www.imanet.org

Kaplan, R. S. (2006). The competitive advantage of management accounting. J. Manage Account Res., 18, 127-135. http://dx.doi.org/10.2308/jmar.2006.18.1.127

Kullven, H., \& Mattson, J. (1994). A management control model based on the customer service process. International Journal of Service Industry Management, 5(3), 14-25. http://dx.doi.org/10.1108/09564239410064043

Lambert, D., \& Whitworth, J. (1996). How ABC can help service organizations. CMA, Magazine, 70, 24-28.

McGowan, A. S. (1998). Perceived Benefits of ABCM Implementation. Accounting Horizons, 12(1), 31-50. Retrieved from https://books.google.com.sg

Peter, B., Turney, B., \& Bruce, A. (1989). Accounting for Continuous Improvement. Sloan Management Review. Retrieved from http://sloanreview.mit.edu/article/accounting-for-continuous-improvement

\section{Copyrights}

Copyright for this article is retained by the author(s), with first publication rights granted to the journal.

This is an open-access article distributed under the terms and conditions of the Creative Commons Attribution license (http://creativecommons.org/licenses/by/3.0/). 